\title{
The Effects of an Acute Load of Thyroxine on the Transport and Peripheral Metabolism of Triiodothyronine in Man
}

\author{
Kenneth A. Woeber, Exequiel Hecker, and Sidney H. Ingbar \\ From the Thorndike Memorial Laboratory, Second and Fourth (Harvard) \\ Medical Services, Boston City Hospital, and the Department of Medicine, \\ Harvard Medical School, Boston, Massachusetts 02118
}

A B S T R A C T In order to examine the question of whether thyroxine-binding globulin (TBG) influences significantly the peripheral metabolism of 3,3',5-triiodoL-thyronine $\left(T_{3}\right)$ in vivo, paired studies of the effects of a large intravenous load of $L$-thyroxine $\left(T_{4}\right)$ on the kinetics of ${ }^{131} \mathrm{I}$-labeled $\mathrm{T}_{3}$ metabolism were carried out in five normal subjects. After the $T_{4}$ load, both the early distributive loss of labeled $T_{3}$ from serum and the volume of $T_{3}$ distribution, observed after distribution equilibrium had been attained, were greatly increased. These alterations were consistent with those to be expected from displacement of $T_{3}$ from its extracellular binding sites. After the $\mathrm{T}_{4}$ load, however, the fractional rate of $T_{3}$ turnover was decreased. This finding is ascribed either to competition between $T_{3}$ and $T_{4}$ for common intracellular pathways of degradation or excretion or to displacement of $T_{3}$ from sites of more rapid to sites of less rapid metabolism. These effects of alterations in the binding activity of TBG on the peripheral metabolism of $T_{3}$, together with those previously reported by others, are consistent with the interpretation that $T_{3}$ is significantly bound by $T B G$ in vivo. However, it is suggested that the effects of alterations in the $T_{3}-T B G$ binding interaction on the metabolism of $T_{3}$ are obscured by alterations in the extracellular-cellular partitioning of $T_{4}$ that would result from concurrent alterations in $\mathrm{T}_{4}$-binding by $\mathrm{TBG}$.

\section{INTRODUCTION}

On the basis of in vitro studies, it is clear that 3,3',5-triiodo-L-thyronine $\left(\mathrm{T}_{3}\right)$ is strongly bound by serum proteins since normally no more than a fraction of $1 \%$ of

This work was presented in part at the Annual Meeting of the American Thyroid Association in Chicago in October, 1966 and in part at the Third International Congress of Endocrinology in Mexico City in July 1968.

Received for publication 20 June 1969 and in revised form 27 October 1969. the total $T_{3}$ in serum exists in the free or unbound state (1). Electrophoretic studies have indicated that thyroxine-binding globulin ( $T B G$ ) is the serum protein to which $T_{3}$, like L-thyroxine $\left(T_{4}\right)$, is predominantly bound $(2,3)$. Despite this, it has been reported that clinical states associated with alterations in the binding activity of TBG are not accompanied by alterations in the kinetics of peripheral $\mathrm{T}_{3}$ metabolism in vivo similar to those which occur in the case of $T_{4}$ under the same conditions (4-7). This has been taken to indicate that $T_{3}$ in contrast to $T_{4}$ is not bound by $T B G$ to a significant extent in vivo. To investigate this problem further, we have studied the kinetics of peripheral $T_{3}$ metabolism in normal subjects before and after a single large intravenous dose of $\mathrm{T}_{4}$. It was anticipated that this maneuver would limit the access of $T_{3}$ to binding sites shared by both hormones and therefore would permit an assessment of the influence of such binding sites on the peripheral metabolism of $T_{3}$.

\section{METHODS}

The effects of $T_{4}$ loading on the transport and peripheral metabolism of ${ }^{131} \mathrm{I}$-labeled $\mathrm{T}_{3}$ were assessed in paired studies conducted in five normal subjects. ${ }^{1}$

Assessment of the kinetics of peripheral $T_{s}$ metabolism. This was carried out as described in the companion report (8), except that in four of the five subjects additional blood samples were collected at 20 and $50 \mathrm{~min}$ after injection of the ${ }^{131} \mathrm{I}$-labeled $\mathrm{T}_{3 .}{ }^{2} 1 \mathrm{wk}$ after the injection of ${ }^{131} \mathrm{I}$-labeled $\mathrm{T}_{3}$ for the control study, a blood sample was collected for measurement of the residual trichloroacetic acid (TCA)precipitable ${ }^{131} \mathrm{I}$. Immediately thereafter, an intravenous load of $4 \mathrm{mg}$ of $\mathrm{T}_{4}$ in a $1 \%(\mathrm{w} / \mathrm{v})$ solution of human serum

${ }^{1}$ The five normal subjects studied were among the seven presented in the companion report (8). They included two of the authors, one physician attached to the medical unit, and two fully-informed volunteers. The latter two subjects were hospitalized for the studies.

${ }^{2}$ Obtained from The Radiochemical Centre, Amersham, England. 
TABLE I

The Effects of L-Thyroxine $\left(T_{4}\right)$ Loading on the Early Phase of the Peripheral Metabolism of ${ }^{131}$ I-Labeled 3,3',5-Triiodo-L-Thyronine $\left(T_{3}\right)$

\begin{tabular}{|c|c|c|c|c|c|c|c|c|}
\hline \multirow[b]{2}{*}{ Subject } & \multirow[b]{2}{*}{ Age, Sex } & \multirow{2}{*}{$\begin{array}{c}\text { Body } \\
\text { weight }\end{array}$} & \multirow{2}{*}{\multicolumn{2}{|c|}{$\begin{array}{c}20 \text { min volume of } \\
T_{3} \text { distribution }\end{array}$}} & \multirow{2}{*}{\multicolumn{2}{|c|}{$\begin{array}{l}50 \text { min volume of } \\
T_{3} \text { distribution }\end{array}$}} & \multicolumn{2}{|c|}{50 min TCA-precipitable ${ }^{121}$ I } \\
\hline & & & & & & & \multicolumn{2}{|c|}{20 min TCA-precipitable ${ }^{131} I$} \\
\hline & $y r$ & $k g$ & \multicolumn{2}{|c|}{ liters } & \multicolumn{2}{|c|}{ liters } & \multicolumn{2}{|c|}{$\%$} \\
\hline & & & Control & $T_{4}$ load & Control & $T_{4}$ load & Control & $T_{4}$ load \\
\hline 1 & $31, \mathrm{M}$ & 68 & 9.8 & 14.9 & 13.5 & 18.0 & 73 & 83 \\
\hline 2 & $30, \mathrm{M}$ & 75 & 9.5 & 14.4 & 13.0 & 19.2 & 74 & 75 \\
\hline 3 & 58. M & 53 & 7.0 & 10.8 & 9.1 & 15.2 & 77 & 71 \\
\hline 4 & $39, \mathrm{M}$ & 57 & 9.7 & 11.6 & 12.6 & 16.5 & 76 & 70 \\
\hline Mean & & & 9.0 & 12.9 & 12.0 & 17.2 & 75 & 75 \\
\hline SE & & & 0.7 & 1.0 & 1.0 & 0.9 & 1 & 3 \\
\hline Mean difference & & & \multicolumn{2}{|c|}{3.9} & \multicolumn{2}{|c|}{5.2} & \multicolumn{2}{|c|}{1} \\
\hline sEM difference & & & \multicolumn{2}{|c|}{0.7} & \multicolumn{2}{|c|}{0.6} & \multicolumn{2}{|c|}{5} \\
\hline$P^{*}$ & & & \multicolumn{2}{|c|}{$<0.02$} & \multicolumn{2}{|c|}{$<0.01$} & \multicolumn{2}{|c|}{ NS } \\
\hline
\end{tabular}

* Analysis by the paired $t$ test.

albumin was administered, followed immediately by a second injection of $50 \mu \mathrm{Ci}$ of ${ }^{131}$ I-labeled $\mathrm{T}_{\mathrm{s}}$. In the studies performed after the $T$, load, corrections were made for the concentration in serum of TCA-precipitable ${ }^{131} \mathrm{I}$ remaining from the first injection. The volumes of distribution of $T_{s}$ at 20 and $50 \mathrm{~min}$ were calculated as the quotient of the amount of injected ${ }^{131} \mathrm{I}$ and the concentrations in serum of TCA-precipitable ${ }^{181} \mathrm{I}$ at the corresponding times. This calculation assumed that significant degradation of $T_{3}$ had not yet occurred, a supposition that was borne out by measurement of urinary ${ }^{181} \mathrm{I}$ at these times. ${ }^{3}$ The kinetics of peripheral $T_{3}$ metabolism after attainment of distribution equilibrium were assessed as described in the companion report (8).

Assessment of the per cent of $T$, in serum bound by $T B G$. $0.5-\mathrm{ml}$ aliquots of serum samples obtained from four of the five subjects $20 \mathrm{~min}$ after injection of the ${ }^{181} \mathrm{I}$-labeled $T_{8}$ were subjected to conventional electrophoresis in filter paper sheets in glycine $(0.2 \mathrm{M})$-acetate $(0.13 \mathrm{M})$ buffer at $\mathrm{pH}$ 8.6. In the remaining subject, serum obtained $8 \mathrm{hr}$ after injection of the ${ }^{131} \mathrm{I}$-labeled $T_{3}$ was enriched with a very small quantity of labeled $T_{3}$ before electrophoresis. Serum enriched with ${ }^{181} \mathrm{I}$-labeled $\mathrm{T}_{4} *(2 \mu \mathrm{Ci} / \mathrm{ml})$ was subjected to electrophoresis in another segment of the same filter paper sheet to serve as a radioactive marker. After electrophoresis, the filter paper sheets were cut into $1 \mathrm{~cm}$ strips and then were counted. The counts were plotted on graph paper and the ${ }^{181} I$ in the strips corresponding to the TBG peak in the labeled $T_{4}$ marker was expressed as a per cent of the total ${ }^{131} \mathrm{I}$ in the sample.

Assessment of the per cent of free $T$, in serum. The general equilibrium dialysis method of Oppenheimer, Squef, Surks, and Hauer was employed (10). Aliquots $(100 \mu \mathrm{l})$ of serum samples obtained at least $24 \mathrm{hr}$ after each injection of ${ }^{131}$ I-labeled $T_{8}$ were diluted with $2.40 \mathrm{ml}$ of Krebs-Ringer

${ }^{3}$ Absence of significant deiodination of the administered labeled $T_{8}$ during this period was confirmed by the concurrent administration of inorganic ${ }^{125} \mathrm{I}$ according to a modification of the method of Anbar, Guttman, Rodan, and Stein (9).

'Obtained from Abbott Laboratories, North Chicago, Ill. phosphate buffer (KRP) at $\mathrm{pH} 7.4$ and enriched with 20 $\mu \mathrm{l}$ of a solution which yielded the equivalent of $0.17 \mu \mathrm{g}$ of ${ }^{131}$ I-labeled $\mathrm{T}_{3}$ added per $100 \mathrm{ml}$ of undiluted serum (final dilution of the serum, 1:25.2). $1 \mathrm{ml}$ of the diluted sample was placed in a sac made from dialysis tubing (Union Carbide Corp., New York, size 20) and dialyzed against $5 \mathrm{ml}$ of $\mathrm{KRP}$ in a $25 \mathrm{ml}$ Erlenmeyer flask for $20 \mathrm{hr}$ at $37^{\circ} \mathrm{C}$. After dialysis, aliquots were taken from inside and outside the dialysis sac. To these were added equal volumes of serum containing carrier iodide and a few milligrams of propylthiouracil. The protein was precipitated with cold $20 \%$ TCA. The precipitates were washed twice with cold $5 \%$ TCA, dissolved in $2 \mathrm{~N}$ sodium hydroxide, and made up to a standard volume for counting. Sufficient counts were obtained to reduce the probable counting error to a maximum of $3 \%$. The amount of TCA-precipitable ${ }^{181}$ I per milliliter of dialysate was expressed as a fraction of the amount of TCA-precipitable ${ }^{181} \mathrm{I}$ in the $1 \mathrm{ml}$ of dilute serum within the dialysis sac. To obtain a value for the per cent of free $T_{3}$, this fraction was multiplied by 100 and divided by the dilution factor of the serum within the sac $(1: 25.2)$. Serum samples obtained from a given subject. during the control study and after the $T_{4}$ load were always analyzed concurrently and in duplicate.

Serum butanol-extractable iodine (BEI) This was measured by the method of Benotti and Pino (11).

\section{RESULTS}

The intravenous $T$, load was well tolerated. Three subjects complained of mild lassitude, but no other untoward effects were encountered. The mean value for the serum BEI was $22.4 \mu \mathrm{g} / 100 \mathrm{ml}$ (range, 20.0-26.0)

\footnotetext{
'Performed by the Boston Medical Laboratory, Boston, Mass.

' In the one subject in whom it was measured throughout the study, the urinary excretion of creatine increased from approximately $40 \mathrm{mg} / \mathrm{g}$ of creatinine during the control period to $120 \mathrm{mg} / \mathrm{g}$ of creatinine during the period from 48 to $72 \mathrm{hr}$ after the $\mathrm{T}_{4}$ load.
} 
TABLE II

The Effects of L-Thyroxine $\left(T_{4}\right)$ Loading on the Peripheral Metabolism of ${ }^{131} I$-Labeled 3,3',5-Triiodo-L-Thyronine ( $\left.T_{3}\right)$ after Attainment of Distribution Equilibrium

\begin{tabular}{|c|c|c|c|c|c|c|c|c|c|c|}
\hline \multirow[t]{3}{*}{ Subject } & \multirow{3}{*}{$\frac{\text { Age, Sex }}{y r}$} & \multirow{3}{*}{$\begin{array}{c}\begin{array}{c}\text { Body } \\
\text { weight }\end{array} \\
k g\end{array}$} & \multicolumn{2}{|c|}{$\begin{array}{l}\text { Volume of } T_{3} \\
\text { distribution }\end{array}$} & \multicolumn{2}{|c|}{$\begin{array}{l}\text { Fractional } \mathrm{T}_{3} \\
\text { turnover rate }\end{array}$} & \multicolumn{2}{|c|}{$T_{3}$ clearance rate } & \multicolumn{2}{|c|}{ Urinary maximum } \\
\hline & & & \multicolumn{2}{|c|}{ liters } & \multicolumn{2}{|c|}{$\% / 24 h r$} & \multicolumn{2}{|c|}{ liters $/ 24 \mathrm{hr}$} & \multicolumn{2}{|c|}{$\%$ dose } \\
\hline & & & Control & $T_{4}$ load & Control & $T_{4}$ load & Control & $T_{4}$ load & Control & $T_{4}$ load \\
\hline 1 & $31, \mathrm{M}$ & 68 & 43 & 54 & 67 & 57 & 28.8 & 30.8 & 83 & 86 \\
\hline 2 & $30, \mathrm{M}$ & 75 & 46 & 61 & 60 & 44 & 27.6 & 26.8 & 81 & 93 \\
\hline 3 & $58, \mathrm{M}$ & 53 & 34 & 64 & 45 & 35 & 15.3 & 22.4 & 54 & 71 \\
\hline 4 & $39, \mathrm{M}$ & 57 & 41 & 47 & 68 & 56 & 27.9 & 26.3 & 70 & 73 \\
\hline 5 & $38, \mathrm{M}$ & 74 & 43 & 64 & 40 & 34 & 17.2 & 21.8 & 91 & 93 \\
\hline Mean & - & & 41 & 58 & 56 & 45 & 23.4 & 25.6 & 76 & 83 \\
\hline $\mathrm{SE}$ & & & 2 & 3 & 6 & 5 & 2.9 & 1.6 & 6 & 5 \\
\hline Mean difference & & & \multicolumn{2}{|c|}{17} & \multicolumn{2}{|c|}{11} & \multicolumn{2}{|c|}{2.3} & \multicolumn{2}{|c|}{7} \\
\hline SEM difference & & & \multicolumn{2}{|c|}{4} & \multicolumn{2}{|c|}{2} & \multicolumn{2}{|c|}{$1 . \bar{c}$} & \multicolumn{2}{|c|}{3} \\
\hline$P^{*}$ & & & \multicolumn{2}{|c|}{$<0.02$} & \multicolumn{2}{|c|}{$<0.01$} & \multicolumn{2}{|c|}{ NS } & \multicolumn{2}{|c|}{ NS } \\
\hline
\end{tabular}

* Analysis by the paired $t$ test.

20 min after the $\mathrm{T}_{4}$ load, $16.0 \mu \mathrm{g} / 100 \mathrm{ml}$ (range, 14.817.4 ) at $24 \mathrm{hr}$, and $13.7 \mu \mathrm{g} / 100 \mathrm{ml}$ (range, 12.2-15.0) at $72 \mathrm{hr}$.

Table I presents the values for the volumes of distribution of ${ }^{131} \mathrm{I}$-labeled $\mathrm{T}_{3}$ at 20 and $50 \mathrm{~min}$ after injection and the effects thereon of $T_{4}$ loading. The mean control value for the volume of distribution of $\mathrm{T}_{3}$ at $20 \mathrm{~min}$ was $9.0 \pm 0.7$ liters (mean $\pm \mathrm{SE}$ ), and at $50 \mathrm{~min}, 12.0$ \pm 1.0 liters. $T$ \& loading was consistently followed by major increases in the volumes of distribution of $T_{3}$ at both times; and for the group as a whole, these increases were significant statistically. The fractional rate of disappearance of $\mathrm{T}_{3}$ from 20 to $50 \mathrm{~min}$, as judged from the ratio of the concentrations of TCA-precipitable ${ }^{281} \mathrm{I}$ in serum at the two times, did not change after the $\mathrm{T}_{4}$ load.

The volume of distribution and fractional rate of turnover of $\mathrm{T}_{3}$ after attainment of distribution equilibrium and the effects thereon of $\mathrm{T}_{4}$ loading were calculated from the data- obtained from 24 to $72 \mathrm{hr}$ after administration of the ${ }^{131} \mathrm{I}$ labeled $\mathrm{T}_{3}$. Verification that distribution equilibrium of the labeled $\mathrm{T}_{3}$ had been attained by $24 \mathrm{hr}$ was obtained by the method described in the companion report (8). In the control study, the values for the pooled 24-hr fractional rates of disappearance were $54 \pm 2 \%$ (mean \pm SE) during the period from 24 to $48 \mathrm{hr}$ and $55 \pm 1 \%$ during the period from 24 to $72 \mathrm{hr}$. After the $\mathrm{T}_{4}$ load, the corresponding values were both $44 \pm 1 \%$. The excellent agreement of the 24-48 and $24-72 \mathrm{hr}$ values indicated a single exponential rate of disappearance during this time and, therefore, that distribution equilibrium of the residual labeled $T_{3}$ had been attained. Values for the volume of distribution and fractional rate of turnover of $T_{3}$ derived from the data obtained in each subject from 24 to $72 \mathrm{hr}$ after each injection of $T_{3}$ are presented in Table II. $T_{4}$ loading was consistently followed by a major increase in the volume of $T_{3}$ distribution and by a decrease in the fractional rate of $\mathrm{T}_{3}$ turnover. For the group as a whole, both these changes were significant statistically. The calculated rate of $T_{3}$ clearance did not change significantly after the $T_{4}$ load. $T_{4}$ loading was followed by a slight but consistent increase in the calculated value for the proportion of the injected ${ }^{131} \mathrm{I}$ ultimately appearing in the urine (urinary maximum), suggesting that the proportion of ${ }^{181} \mathrm{I}$ ultimately appearing in the feces (fecal maximum) might have decreased. These changes, however, were not significant statistically.

Values for both the proportion of $T_{3}$ bound by $T B G$ and the per cent of free $T_{3}$ in serum are depicted in Fig. 1. $T_{4}$ loading was consistently followed by a decrease in the proportion of $T_{3}$ bound by TBG and by an increase in the per cent of free $T_{3}$ in serum; for the group as a whole, both these changes were significant statistically.

\section{DISCUSSION}

It has generally been accepted that phenomena related to the binding of thyroid hormones in vitro provide a qualitatively accurate reflection of the thyroid hormoneprotein binding interactions that pertain in vivo. Within the framework of the concept that the extracellular binding of hormone limits the access of hormone to the tissues, the many circumstances in which alterations in $T_{4}$ binding, as assessed in vitro, are associated with predictable reciprocal alterations in the rate of clearance of $T_{4}$ in vivo have tended to support the applicability of in vitro binding phenomena. A large body of data 
obtained in vitro suggests that TBG is the major binding protein for $\mathrm{T}_{3}(2,3)$. Nevertheless, several recent observations indicate that changes in the binding activity of TBG do not produce alterations in the in vivo metabolism of $T_{3}$ similar to those which occur in the case of $T_{4}(4-7)$. Consequently, it has been suggested that $T_{3}$ is not bound to $T B G$ in vivo to a significant extent. This conclusion challenges the relevance of in vitro binding phenomena to the in vivo situation not only in the case of $T_{3}$ but also with respect to $T_{4}$.

Two lines of evidence derived from kinetic data have been taken to indicate that $T_{3}$ is not bound to a significant extent by TBG in vivo. First, Zaninovich, Farach, Ezrin, and Volpé have reported that alterations in the binding activity of TBG do not influence the rate of disappearance of ${ }^{131} \mathrm{I}$-labeled $\mathrm{T}_{3}$ from serum during the period from 20 to $50 \mathrm{~min}$ after its intravenous administration (4). On the other hand, similarly induced alterations in the binding activity of TBG did produce the expected alterations in the rate of disappearance of $T_{*}$ during the same period. In order to examine this interesting observation further, we have attempted to disrupt the extracellular $\mathrm{T}_{3}-\mathrm{TBG}$ binding interaction by saturating the binding sites on TBG through the administration of a large $T$, load. In common with the findings cited above, the rate of disappearance of $T_{8}$ from serum during the period from 20 to $50 \mathrm{~min}$ was unaltered. On the other hand, calculated volumes of distribution were greatly increased by the $T_{4}$ load. The interpretation of such findings is exceedingly complex.

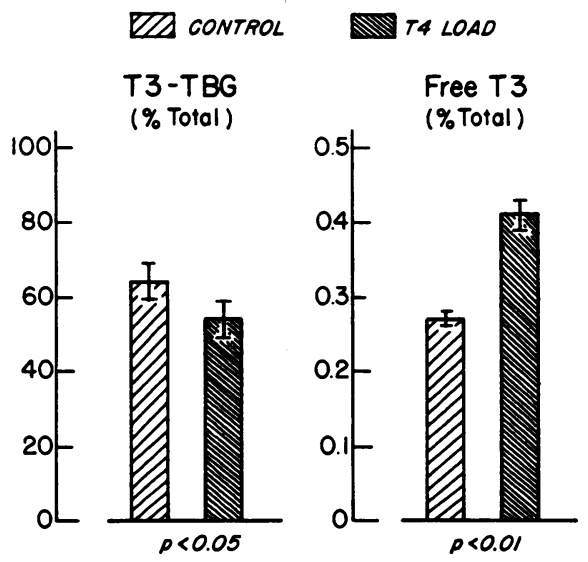

FIGURE 1 The effects of an intravenous load of L-thyroxine $\left(\mathrm{T}_{4}\right)$ on the in vitro binding of $3,3^{\prime}, 5$-triiodo-L-thyronine $\left(\mathrm{T}_{3}\right)$ in serum. $\mathrm{T}_{3}$-TBG refers to the per cent of labeled $\mathrm{T}_{3}$ bound by $T_{4}$-binding globulin (TBG), as assessed by conventional filter paper electrophoresis of serum obtained after an intravenous tracer dose of ${ }^{131} \mathrm{I}$-labeled $\mathrm{T}_{3}$. In vitro enrichment with a very small quantity of ${ }^{131} \mathrm{I}$-labeled $\mathrm{T}_{\mathbf{8}}$ was required in only one instance before electrophoresis. The mean $\pm \mathrm{SE}$ of the values obtained in the five subjects are shown.
Before the attainment of distribution equilibrium, the conceptual differentiation between volume of distribution and fractional rate of disappearance is probably spurious. It is apparent that if $T_{4}$ loading increased the volume of distribution of $\mathrm{T}_{3}$ at $20 \mathrm{~min}$, then it must also have increased the rate of disappearance of $T_{3}$ from serum before that time. It is clear that the degradation of $\mathrm{T}_{3}$ during this early period is negligible. Hence, the disappearance of $T_{3}$ from serum is totally a reflection of distribution. Whether viewed as an increase in the volume of distribution at $20 \mathrm{~min}$ or as an increased rate of disappearance before $20 \mathrm{~min}$, the present data indicate a greater early distributive loss of $T_{3}$ from serum after the $T_{4}$ load. This is consistent with the classical binding concept since the $T_{4}$ load would be expected to increase the proportion of free $\mathrm{T}_{3}$ (as was actually observed in vitro), and it is generally held that the free hormone is more readily accessible to the tissues. Thus, the present data suggest that $T_{3}$ is significantly bound in vivo and that such binding can be disrupted by an increase in the concentration of $T_{4}$; they do not, however, bear upon the question as to whether $T_{3}$ is significantly bound by TBG per se. Evidence bearing upon this question is discussed below.

The second line of evidence from which it has been concluded that $T_{3}$ is not significantly bound by $T B G$ in vivo derives from studies of the effects of alterations in the binding activity of TBG on the kinetics of peripheral $T_{3}$ metabolism after distribution equilibrium has been attained (5-7). Thus, several studies have demonstrated that when the binding activity of TBG is increased the fractional rate of $\mathrm{T}_{3}$ turnover is enhanced and that when the binding activity of TBG is decreased the fractional rate of $T_{3}$ turnover is diminished. These alterations are the converse of those observed in the case of $T_{4}$ (see review, reference 12 ). In the present study, $T_{4}$ loading was associated with an increase in the ultimate volume of distribution of $T_{3}$, a change again consistent with that to be expected from a disruption of the extracellular binding of $\mathrm{T}_{3}$. However, the fractional rate of turnover of $T_{3}$ was decreased after the $T_{4}$ load. This observation is concordant with the previously observed effects on $T_{3}$ turnover produced by primary alterations in the binding activity of TBG cited immediately above. Although these alterations in the fractional rate of $T_{3}$ turnover appear superficially inconsistent with the expected effects of a $T_{3}$-TBG binding interaction, they do not constitute evidence that $T_{3}$ is not significantly bound by $T B G$ in vivo. If $T_{3}$ were indeed not bound by TBG, one would expect that alterations in the binding activity of TBG would have no effect on the metabolism of $T_{3}$; such is obviously not the case. Hence, it must be concluded that regardless of 
whether $T_{3}$ is bound by TBG, alterations in the binding activity of TBG lead to some other change which in turn is reflected in the observed alterations in $T_{3}$ metabolism.

The most likely possibility is that the changes in $T_{3}$ metabolism are owing to a redistribution of $T_{4}$, probably into the liver. The few data available would suggest that when there is a primary decrease in the binding activity of TBG $T_{4}$ is shifted to cellular sites, particularly in liver, so that the cellular pool of hormone comprises a greater than normal fraction of the total extrathyroidal pool (13-15). Furthermore, in experiments comparable to those presented here, acute intravenous loads of $T_{4}$ have been shown to produce acute displacement of labeled (and hence stable) $T_{4}$ into extravascular sites, at least partly in the liver (16). Increased localization of $T$, within the liver resulting from either primary decreases in $T B G$ or from $T$, loading could produce the observed alterations in $T_{3}$ metabolism in one of two ways. First, it could inhibit hepatic uptake of $T_{8}$, while permitting enhanced uptake at other sites where $T_{3}$ degradation might occur more slowly. Alternatively, enhanced hepatic uptake of $\mathrm{T}_{\mathbf{s}}$ owing to decreased extracellular binding may occur, but accumulated $T_{4}$ may compete with accumulated $\mathrm{T}_{3}$ for degradative or excretory pathways. Either explanation would be consistent with the slight decrease in the calculated fecal maximum that might have occurred after the $T_{4}$ load since this is a reflection of $T_{3}$ metabolism by the liver.

In conclusion, if it is granted that the data demonstrate that alterations in the binding activity of TBG do influence the peripheral metabolism of $T_{3}$, but that their effects on $T_{s}$ metabolism are secondary to some other change consequent to the alteration in the binding activity of TBG, then it is no longer necessary to postulate that $T_{3}$ is not significantly bound by $T B G$ in vivo. One need only postulate that the secondary effects on $T_{\mathbf{3}}$ metabolism preponderate over the primary effects of alterations in the $T_{3}-T B G$ binding interaction. The latter conclusion would tend to preserve intellectual order and would be in accord with the great likelihood that in vitro binding interactions of $T_{3}$ do qualitatively reflect those that occur in vivo.

\section{ACKNOWLEDGMENTS}

This work was supported in part by Research Grant AM09753 from the National Institute of Arthritis and Metabolic Diseases, and by Grant FR-76 from The Division of Research Facilities and Resources, National Institutes of Health, Bethesda, Md.

\section{REFERENCES}

1. Ingbar, S. H., L. E. Braverman, N. A. Dawber, and G. Y. Lee. 1965. A new method for measuring the free thyroid hormone in human serum and an analysis of the factors that influence its concentration. J. Clin. Invest. 44: 1679.

2. Mitchell, M. L., A. H. Bradford, and S. Collins. 1964. Differences in the interaction of triiodothyronine- ${ }^{131} \mathrm{I}$ with serum proteins in vitro. J. Clin. Endocrinol. Metab. 24: 867.

3. Braverman, L. E., and S. H. Ingbar. 1965. Binding of $3,5,3^{\prime}$-L-triiodothyronine in human serum during agar gel electrophoresis at $\mathrm{pH}$ 7.4. Endocrinology. 76: 547 .

4. Zaninovich, A. A., H. Farach, C. Ezrin, and R. Volpé. 1966. Lack of significant binding of L-triiodothyronine by thyroxine-binding globulin in vivo as demonstrated by acute disappearance of ${ }^{181} \mathrm{I}$-labeled triiodothyronine. $J$. Clin. Invest. $45: 1290$.

5. Zaninovich, A. A., R. J. Soto, R. Volpé, and C. Ezrin. 1967. The peripheral interaction of $T_{4}$ and $T_{3}$ in estrogen treated human subjects. Abstracts of the American Thyroid Association. 37.

6. Zaninovich, A. A., R. J. Soto, R. Volpé, and C. Ezrin. 1968. Effects of androgens and diphenylhydantoin (DPH) on the late phase of $T_{3}$ disappearance from the circulation. Excerpta Med. Int. Congr. Ser. 157: 474. (Abstr.)

7. Dussault, J., V. V. Row, and R. Volpé. 1969. The effect of alterations of thyroxine binding globulin (TBG) on triiodothyronine $\left(\mathrm{T}_{3}\right)$ dynamics. Abstracts of the $51 \mathrm{st}$ Meeting of the Endocrine Society. 76.

8. Woeber, K. A., R. J. Sobel, S. H. Ingbar, and K. Sterling. 1969. The peripheral metabolism of triiodothyronine in normal subjects and in patients with hyperthyroidism. J. Clin. Invest. 49: 643 .

9. Anbar, M., S. Guttmann, G. Rodan, and J. A. Stein. 1965. The determination of the rate of deiodination of thyroxine in human subjects. J. Clin. Invest. 44: 1986.

10. Oppenheimer, J. H., R. Squef, M. I. Surks, and H. Hauer. 1963. Binding of thyroxine by serum proteins evaluated by equilibrium dialysis and electrophoretic techniques. Alterations in nonthyroidal illness. J. Clin. Invest. 42 : 1769.

11. Benotti, J., and S. Pino. 1966. A simplified method for butanol-extractable iodine and butanol-insoluble iodine. Clin. Chem. 12: 491.

12. Oppenheimer, J. H. 1968. Role of plasma proteins in the binding, distribution and metabolism of the thyroid hormones. N. Engl. J. Med. 278: 1153 .

13. Cavalieri, R. R., and G. L. Searle. 1966. The kinetics of distribution between plasma and liver of ${ }^{131} \mathrm{I}$-labeled L-thyroxine in man: observations of subjects with normal and decreased serum thyroxine-binding globulin. J. Clin. Invest. 45 : 939.

14. Nicoloff, J. T., and J. T. Dowling. 1968. Studies of peripheral thyroxine distribution in thyrotoxicosis and hypothyroidism. J. Clin. Invest. 47: 2000.

15. Oppenheimer, J. H., G. Bernstein, and J. Hasen. 1967. Estimation of rapidly exchangeable cellular thyroxine from the plasma disappearance curves of simultaneously administered thyroxine- ${ }^{181} \mathrm{I}$ and albumin ${ }^{-25} \mathrm{I}$. J. Clin. Invest. 46: 762 .

16. Ingbar, S. H., and N. Freinkel. 1960. Regulation of the peripheral metabolism of the thyroid hormones. Recent Progr. Hormone Res. 16: 353. 